\title{
Localised Mobile Learning Solutions: Responding to the Needs of Global Education
}

\author{
Päivi Aarreniemi-Jokipelto ${ }^{1}$, Elias E. Goulart ${ }^{2}$ \\ ${ }^{1}$ Haaga-Helia University of Applied Sciences, School of Vocational Teacher Education, \\ Ratapihantie 13, 00520, Helsinki, Finland. \\ ${ }^{2}$ Laboratório de Hipermídias, University of Sao Caetano do Sul, Brazil (USCS), \\ Rua Santo Antonio 50, Centro, São Caetano do Sul, SP, Brasil. \\ \{paivi.aarreniemi-jokipelto@haaga-helia.fi, elias.goulart@uscs.edu.br\}
}

\begin{abstract}
Mobile phone penetration has increased considerably throughout the world, and it reached $142 \%$ in Brazil in 2015. In addition to the strong trend of mobile device usage in free time, there has been an increase in use for learning purposes. Mobile devices can deliver learning to people, communities, and countries where other educational inventions have been too expensive, difficult, dangerous, or demanding. The objective of the present study was to test if existing e-learning solutions could be localised to enable mobile learning in Brazil. Another aim of the study was to develop a mobile learning taxonomy defining the criteria for localising mobile learning in global education, to tailor it to different circumstances and cultures.
\end{abstract}

\section{Introduction}

Mobile learning (or M-learning) refers to the process of learning mediated by mobile technologies, such as smartphones, tablets, and video game consoles [Schuler, Winters, \& West, 2012]. According to [Pegrum 2014], mobility not only refers to devices but also to learners and learning itself. The learners' mobility means that they are on the move, outside of school, studying via the use of electronic devices. The mobility of learning means that the learning situation itself can be mobile. Learners are creating learning situations by using mobile devices to access needed information or to create something (e.g. making an audio or video recording, taking a picture). This action occurs in a moment, and a device is needed in that moment for the learning to take place. Furthermore, as [Pegrum 2014] points out, there have been suggestions to apply mobility to the wider society and era in which the learning is taking place. However, it is difficult to separate the mobility of the devices, the learners, the learning, the society, and the era. The pilot study discussed in this paper focused on the mobility of devices and examined a context in which M-learning solutions were used in a classroom, aided by mobile devices. However, we can assume that in the future, the learning solutions discussed in this paper will be further developed for learning situations where the learners themselves are mobile.

Conversations abound concerning the role of mobile devices in school. Smartphones and mobile phones can be great educational tools, but they can also cause a distraction in the classroom. However, in today's technological world, it is important that students learn the necessary skills and competencies for keeping up in the 
digitalised world. According to [Redecker et al. 2011], technology-enabled learning is a future trend which will require new competencies from citizens. Therefore, technological awareness and the willingness to learn to use new technologies are important competencies, not just from the personal point of view but also from the societal viewpoint. The best way to manage the use of technology in the classroom is not to ignore it but to ensure that it brings added value to learning. Inside the classroom, M-learning gives teachers and learners increased flexibility and new opportunities for learning situations, but it also allows teaching and learning to extend to spaces beyond the traditional classroom.

Students and teachers are using mobile devices to access educational content, to converse, to share and construct information with peers, to elicit support from other students and teachers, and to facilitate communication [Pisa \& Goulart 2017]. Mobile devices can deliver learning to people, communities, and countries where other educational inventions have been too expensive, difficult, dangerous, or demanding [Traxler \& Kukulska-Hulme 2016]. According to [UNESCO 2013], mobile technologies provide an excellent medium for extending educational opportunities to learners, who may not have access to high-quality schooling.

As of April 2015, Brazil had a population of just over 200 million people and a mobile penetration rate of $142 \%$. In fact, Brazil accounts for one third of all mobile users in Latin America and is adding one million mobile subscriptions per month. Over $38 \%$ of the population was accessing the Web via mobile devices as of May 2015 and 8.7 million of them were using mobile devices exclusively to access the Internet [Ambient Insight 2015].

\section{Methods}

Design science research was the approach utilised in the study. A design scientist attempts to engineer innovative educational environments while simultaneously conducting experimental studies on those innovations [Brown 1992]. The objective of this study was to gain an understanding of the existing mathematics, English, and Java learning services used in contact learning environments through mobile devices. Design science research consists of two activities: building and evaluation [Järvinen 2001]. Building refers to the process employed to construct an innovation, artefact, or model for a specific purpose. In the context of the present study, building refers to the process of tailoring existing e-learning solutions to M-learning solutions. Evaluation refers to determining how well the innovation, artefact, or model is performing. In evaluating Mlearning solutions, the question arises as to whether they are, in some sense, superior to the teaching and learning methods used previously in the same situations. The main condition of validity for construction is that it solves the problems in question [Kasanen et al., 1993].

The main research question was as follows: Is it possible to localise existing elearning courses in mathematics, Java programming, and English to ensure that they are effective for teaching Brazilian students through mobile devices?

The following were the secondary questions: 
VI Congresso Brasileiro de Informática na Educação (CBIE 2017)

Anais do XXVIII Simpósio Brasileiro de Informática na Educação (SBIE 2017)

1. What are the criteria for localising M-learning solutions in global education in different circumstances and cultures?

2. Are M-learning solutions able to bring added value to learners?

3. Is it possible to use the 'bring your own device' (BYOD) concept in Brazilian schools?

\section{Study}

The study was conducted as part of an international joint research project involving three research partners: one in Brazil and two in Finland. The project has three Finnish company partners (Finpeda, Promentor, and Viope) which are testing their products in Brazil. The following figure illustrates the conceptual model of the study.

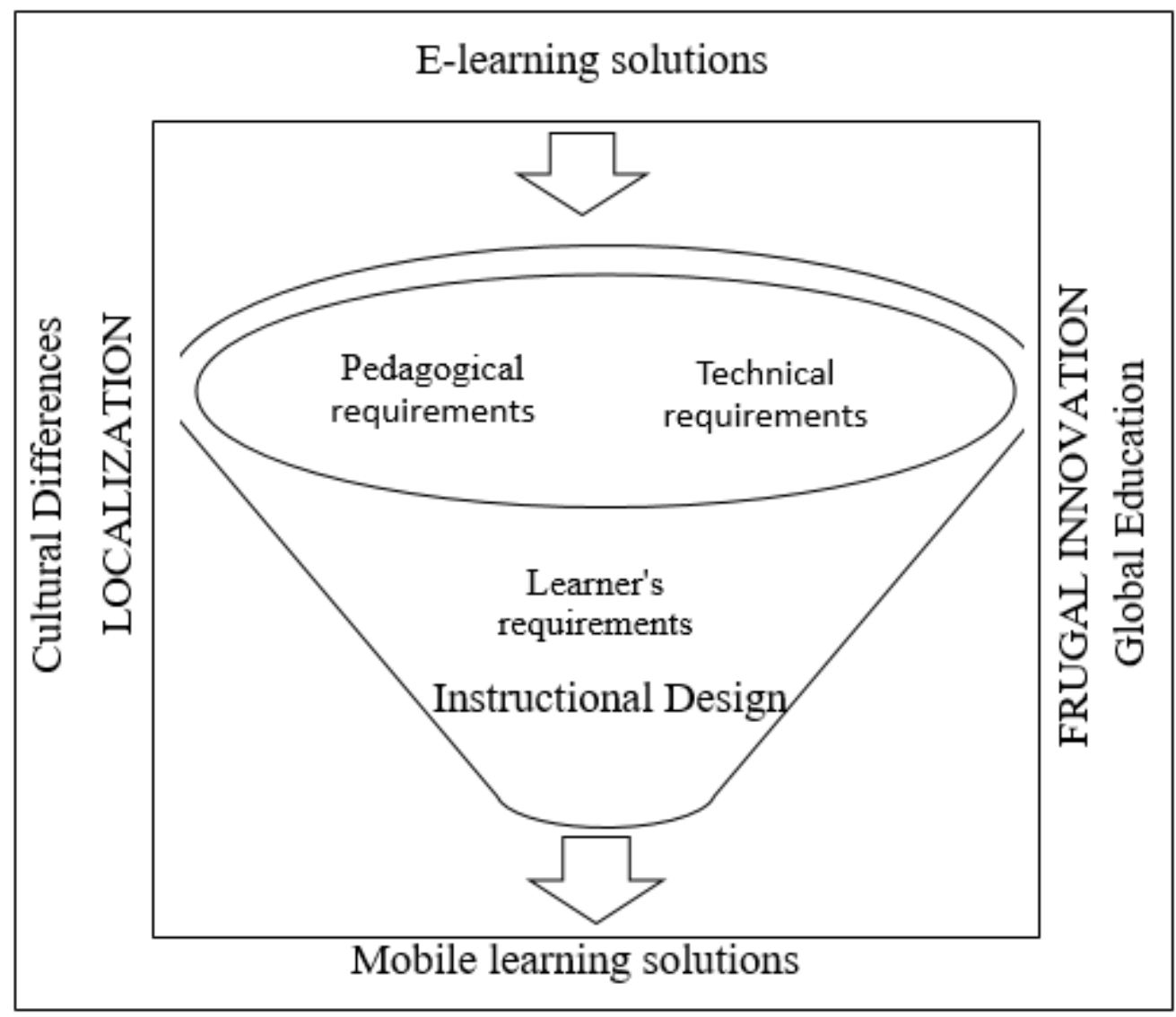

Figure 1. Conceptual model for development and design of localised M-learning solutions

The project partner company Viope (www.viope.com) provides e-learning solutions in mathematics, and Java programming, Promentor (http://www.promentor.fi/en/) in English, and Finpeda (http://finpeda.fi/) has a 3D virtual space. However, in this paper, we concentrate on the e-learning solutions of the former two companies. The existing e-learning solutions are already used in many Finnish institutions, and the companies have taken steps to expand to global markets. However, they are interested in knowing if their learning solutions can be applied through mobile devices in emerging markets. Owing to its high mobile penetration and 
VI Congresso Brasileiro de Informática na Educação (CBIE 2017)

Anais do XXVIII Simpósio Brasileiro de Informática na Educação (SBIE 2017)

increasing Web use via mobile devices, Brazil has been chosen as the testing environment.

In addition to M-learning, frugal innovation was selected as another theoretical framework of the project. According to [Herstatt and Tiwari 2012], 'Frugal innovations are new or significantly improved products (both goods and services), processes, or marketing and organizational methods that seek to minimize the use of material and financial resources in the complete value chain (development, manufacturing, distribution, consumption and disposal) with the objective of reducing the cost of ownership while fulfilling or even exceeding certain pre-defined criteria of acceptable quality standards'. Through frugal innovation, economically disadvantaged countries have been able to solve various problems pertaining to education [Khan 2016]. In this study, we used existing e-learning solutions to minimise the costs, but the objective was to develop M-learning solutions that fulfil or exceed the needs of Brazilian education in the education context.

The existing e-learning solutions have been used in Finland and in some other countries, but never in Brazil. As is evident, there are cultural differences between Latin American countries and Nordic countries; therefore, there is a need to localise the learning services according to the circumstances in Brazil. The pedagogical, technical, and personal requirements of the conceptual model were adopted from an existing Tlearning (interactive digital TV learning) model [Aarreniemi-Jokipelto 2006] to form a basis for categorising localised M-learning criteria to enable the analysis of the results of the tests carried out in Brazil. Ultimately, the defined localised M-learning criteria will serve as a tool for the instructional design and development of M-learning services in global markets. This paper describes the novel criteria for localised M-learning services and makes improvement suggestions for the companies to cater to the local circumstances and needs.

\section{Pilot study phase in Brazil}

The Brazilian partners in the pilot study were Municipal University of São Caetano do Sul (USCS), Escola Estadual Professora Brisabella de Almeida Nobre (Brisabella), Fundação Santo Andre (FSA), and EME Prof ${ }^{a}$ Alcina Dantas Feijão (Alcina). The pilot study phase was organised with eight teachers in the four Brazilian educational institutions in March 2017. The Brazilian research partner, USCS, had trained the teachers to familiarise them with the existing e-learning solutions, and the teachers had chosen the learning content they wanted to use in the pilot study. The learning material and platforms were in English, but when necessary, the project could translate the learning material and platform from English to Portuguese. The teachers were encouraged to design learning situations in which M-learning solutions could bring added value to the learning in the classroom.

The pilot study began on a Monday night at FSA with a math learning solution from Viope. In total, 29 students between the ages of 18 and 46 years participated. On Tuesday morning, Promentor's English learning solution was tested in basic education at Brisabella. The 36 participating students were about 12 years old. In the afternoon at Alcina, a math solution was piloted by 16 students aged 13 to 14 years. In the evening, Viope's Java learning solution was shared with 19 vocational students. Later in the 
evening, eight adult students from vocational education tested an English solution. On Wednesday, 26 students between 15 and 16 years piloted the math solution at Brisabella. On Thursday evening at FSA, the English solution was tested by 46 students between 19 and 27 years. Subsequently, Viope's Java programming learning services were tested by 27 students from Computer Science course at USCS.

At the beginning of the pilot study, students filled in a questionnaire. In most cases, the questionnaire was in paper form, but in a few cases, the information was collected via an electronic form. There were 11 questions aimed at obtaining the following information: (1) gender, (2) age, (3) type of media used for studying, (4) types of sites used for studying, (5) number of teachers who allow the use of mobile phones in the classroom, (6) comments about the test or suggestions to contribute to the project, (7) main apps used for studying, (8) main sites used for studying, (9) suggestions on the use of mobile devices in learning, (10) suggested content or subjects, and (11) use of social media as a tool for learning and how it can be used.

Three researchers were present in all classrooms where these learning solutions were being tested, to observe the students' and teachers' work. In addition to observing, the Brazilian professor had the important role of presenting the study to the students, instructing the students during the study, and solving the challenges students faced during the testing process. The two Finnish researchers concentrated more on observing and writing notes about what they saw and recording the students' and teachers' comments on the learning solutions.

Viope's Java programming and mathematics content and Promentor's English electronic content formed the core of the first piloting phase of this research at the beginning of 2017. As these learning solutions have yet to be optimised for mobile device usage, students tested them primarily on smartphones, but via a browser. Additionally, some student groups combined smartphones and PCs in the learning situations. The most common operating system on the students' smartphones was Android, and the phones varied from expensive smartphones to cheaper ones.

For the younger students, teachers developed the instructional design for the pilot study as part of the students' learning process and led the testing via a laptop that was mirrored on a screen for the whole classroom. In other learning situations, students had the freedom to test the learning solutions at their own speed and in the order of their choosing.

Afterwards, a meeting between the teachers and researchers was organised to receive the teachers' feedback on the mobile solutions and to hear their suggestions about how to improve the learning solutions to meet the circumstances and needs of the Brazilian education system. Five teachers participated in the feedback meeting.

\section{Results}

When categorising the received feedback and observation notes, it became evident that most of the feedback was related to technological criteria. While there were also needs associated with pedagogical or learners' personal criteria, which are commonly seen as very important in digital learning, the biggest challenges faced in the first pilot study were related to the mobile devices and infrastructure. The situation will probably be 
VI Congresso Brasileiro de Informática na Educação (CBIE 2017)

Anais do XXVIII Simpósio Brasileiro de Informática na Educação (SBIE 2017)

different in the second pilot study, when the improved M-learning solutions are deployed.

As stated, the learning solutions used in the pilot study were not optimised for mobile devices. Therefore, the most typical feedback resulted from the use of browserbased solutions, which were not favoured by the students. The most typical feedback concerned scaling challenges. When a mobile device was in a horizontal position, the keyboard covered almost half of the screen, making it difficult to see the learning content. In addition, there were situations where some of the content was obscured in the horizontal position. When the phone was in a vertical position, the content scaled better on the screen, and consequently the user experience was better. There were also challenges depending on the operating system, browser, or device; some students using a different phone model or operating system did not encounter the same challenges as other students. Therefore, it is important that the solutions be adaptable to different operating systems and devices. Accordingly, a recommendation for the companies is to develop an application which works on different devices.

There were also challenges related to infrastructure. The number of classrooms equipped with a Wi-Fi connection was typically very limited. It was common for a school to have two classrooms, for example, with Wi-Fi connectivity. Another issue was that during thunder and heavy rain, Internet access was not always reliable. In addition, the Internet speed varied considerably and was very slow at times. To solve such infrastructure-related challenges, offline solutions, which do not require Internet access for studying, would be indispensable. In that case, it would be possible for users to download learning solutions on their mobile devices beforehand and study whenever they wish, regardless of the availability of Internet access. It would also allow for using the solutions outside the classroom, such as while travelling to school or home.

The main feedback on the pedagogical criteria related to the lack of study instructions for the M-learning solutions. Students needed instructions on how to study using the M-learning solutions. A request was made for instructions on how to write mathematical sentences. For example, after a trial, students reported that it was a mandatory to use parentheses () to receive a correct answer. In addition, all the steps had to be written in a mathematical sentence; it was insufficient to simply write the answer, which irritated the most talented students. Generally, learning to use the service was based on trial and error. Students requested a video form of the study instructions to improve the pedagogical learnability and usability of the learning solutions. There was also a request to make the experience more visual, including pictures and videos, instead using strictly text.

There were numerous challenges in translating the learning solutions. The Brazilian teachers had made decisions about what needed to be translated, but the translations were not done according to their requests. The final outcome was typically a mixture of several languages; for instance, the newsletter was in Finnish, although the chosen language was Portuguese. Sometimes the chosen language disappeared completely when opening a new page. To ensure coherent language in translations of the learning materials and platforms, these should be checked carefully to ensure a fruitful learning experience before the learning solutions can be adopted by a wider audience. 
There were also challenges concerning navigation in the learning solutions. Some students did not recognise the buttons meant to take them to the next or previous page, because they were looking for the buttons on the other side of the screen. This can be solved either by changing the position of the navigation buttons or by providing instructions describing the navigation principles. There was also a shortcut to a theory part, but the theory part did not exist. Moreover, there was a challenge of combining navigation and the language choice. If a Portuguese version of the course was used, the user was not allowed to proceed to the next assignment, but the same problem did not occur when using the English version. More coherent navigation in all languages can resolve this issue.

When analysing the challenges regarding learners' personal criteria, the main concern appeared to relate to accessibility. The type of mobile device affected the accessibility of the learning solution. When the bring your own device (BYOD) concept spreads wider in the education field, it should be ensured that students' devices can be used for the designed learning situations. The other option would be for schools to provide the devices for use in learning situations.

The students' willingness to use mobile devices for learning solutions was high in the pilot study. The atmosphere in all classrooms where the M-learning solutions were tested was one characterised by great enthusiasm. The students showed very positive attitudes towards the testing of mobile devices for learning purposes. They felt that this was how they would want to study in the future. Furthermore, the feedback from teachers on the use of mobile devices for learning purposes was very encouraging.

\section{Discussion/Conclusion}

According to the results of the pilot study, it is possible to localise the existing elearning solutions in mathematics, Java programming, and English to teach Brazilian students through the use of mobile devices, but first, the solutions must undergo further development to correspond to the circumstances and needs in Brazil. There were usability challenges because the tested learning solutions had not yet been optimised for mobile device use. As a recommendation, applications and offline solutions should be developed to replace the existing browser-based solutions. In addition, there is a need to further develop and design the pedagogical solutions. It is important to design video instructions to make it easier for students to study. There is also a need to make the content and study instructions more visual by adding videos and pictures. Furthermore, translations must be checked for coherent language and navigability.

The following table illustrates the M-learning taxonomies, in which the dimensions and values are based on the pilot study. The taxonomies are defined in the conceptual model of the study, which is an adaptation of the T-learning model [Aarreniemi-Jokipelto 2006]. The objective of the M-learning taxonomies is to categories criteria that should be considered when M-learning solutions are planned for localisation according to other circumstances or cultures than those in which the solutions were developed. Now, the dimensions are limited to those found in the study, and they will be completed after the second pilot study. 
VI Congresso Brasileiro de Informática na Educação (CBIE 2017)

Anais do XXVIII Simpósio Brasileiro de Informática na Educação (SBIE 2017)

Table 1: M-learning taxonomies for localising M-learning solutions

\begin{tabular}{|c|c|c|}
\hline Taxonomy of & Dimension & Description of values \\
\hline \multirow[t]{6}{*}{ Technology } & Technical solution & application, browser-based solution \\
\hline & Internet connection & online, offline \\
\hline & Connection & Wi-Fi, mobile connection \\
\hline & Device & $\begin{array}{l}\text { mobile phone, smartphone, tablet; names of } \\
\text { the devices }\end{array}$ \\
\hline & Operating system & $\begin{array}{l}\text { Android, Apple iOS, Blackberry OS, } \\
\text { Windows OS, etc. }\end{array}$ \\
\hline & Usability & Types of presentation and navigation \\
\hline \multirow[t]{4}{*}{ Pedagogy } & Role of M-learning & supplementary, partial, substitute \\
\hline & Easiness for studying & intuitive, study instructions needed \\
\hline & Learning situation & $\begin{array}{l}\text { search information, make calculations, } \\
\text { exchanging contents, using specific apps, } \\
\text { collaborating on activities, developing } \\
\text { projects. }\end{array}$ \\
\hline & $\begin{array}{l}\text { Learning content: } \\
\text { - } \text { purpose } \\
\text { - form } \\
\text { - type } \\
\text { - language, } \\
\text { translations } \\
\text { - } \text { navigation }\end{array}$ & $\begin{array}{l}\text { designed for learning purposes, } \\
\text { designed for other purposes } \\
\text { - learning material, instructions, } \\
\text { assignments, quizzes } \\
\text { - text, picture, video, audio } \\
\text { - consistent, inconsistent } \\
\text { - intuitive, not intuitive }\end{array}$ \\
\hline \multirow[t]{2}{*}{ Learner } & Accessibility & regional, technical \\
\hline & Motivation & high, medium, slow \\
\hline
\end{tabular}

According to many studies, M-learning solutions can bring added value to learning [e.g. Pegrum 2014]. Due to the small size and portability of a mobile device, learning can occur anywhere and anytime. Furthermore, a learner can easily generate his/her own content in a real-life situation in the form of an audio file, a picture or a video, but many other advantages have also been reported. This pilot study evinced that there are other advantages of M-learning. The first one is students' tremendous 
motivation to use mobile devices for learning. As one participant commented, 'This is the way that we want to study'. It was amazing to witness how engaged they were in the learning situation. However, as we observed each group only once, the question arises as to whether this influenced the received feedback. We cannot state with certainty if we would have received the same comments if the students had used the devices for three months or more. This will be addressed in the second pilot study.

According to the Horizon report [NMC 2015], future trends in higher education in Brazil will include the BYOD concept and the use of mobile apps, which are estimated to be adopted in two years. Therefore, the BYOD should be a reality in Brazil now. In the pilot study, students used their own mobile devices, thereby utilising the BYOD concept. However, whether students are able to adopt the BYOD concept across Brazil remains unknown. After the pilot week, there was an opportunity to observe Mlearning use in the state of Piauí, which is one of the poorest states in Brazil. Some students used their own devices in class, but the school had also bought mobile devices for classroom use. This was because students had been afraid to bring their own devices to school, due to fear that the devices could be robbed during the journey to school or home. Regardless of the Horizon report's estimation that BYOD will be a trend in Brazil in 2017, this does not look likely, at least not yet. There are teachers and schools utilising the concept, but so far, it cannot be called a trend in Brazil.

The next phase of the research will be to develop two applications for the two companies to be piloted in Brazil later this year. The objective will be to solve the challenges faced in the first pilot study, but also to further develop the presented Mlearning taxonomies to localise M-learning services in global education to suit different circumstances and cultures.

\section{References}

Aarreniemi-Jokipelto, P. (2006). Doctoral Dissertation: Modelling and content production of distance learning concept for interactive digital television. Helsinki University of Technology, Industrial Information Technology Laboratory publications, 4.

Available:

https://aaltodoc.aalto.fi/handle/123456789/5/browse?value=Aarreniemi-

Jokipelto\%2C+P\%C3\%A4ivi\&type=author .

Ambient Insight. (2015). Adkins. S. Ambient Insight's 2014-2019 Brazil Mobile Learning Market. Available:_www.ambientinsight.com/Reports/MobileLearning.aspx 6 April, 2017.

Brown, A. (1992). Design Experiments: Theoretical and Methodological Challenges in Creating Complex Interventions in Classroom Settings. The Journal of the Learning Sciences. 2(2), 141-178.

Herstatt, C. and Tiwari, R. (2015) Frugale Innovation: Wissenschaftliche Einordnung eines neuen Innovationsbegriffs, Arbeitspapier Nr. 88, Technische Universität Hamburg-Harburg.

Järvinen, P. (2001). On research methods. Opinpajan kirjat, Tampereen yliopistopaino Oy. Tampere. 
VI Congresso Brasileiro de Informática na Educação (CBIE 2017)

Anais do XXVIII Simpósio Brasileiro de Informática na Educação (SBIE 2017)

Kasanen, E., Lukka, K., Siitonen, A. (1993). The constructive approach in management accounting research, Journal of management accounting research, 5, 243-264.

Khan, R. (2016). How Frugal Innovation Promotes Social Sustainability, Sustainability 2016, 8(10), 1034; Available: doi:10.3390/su8101034. 6 June 2017.

NMC. (2015). NMC Technology Outlook. Brazilian Universities, A Horizon Project Regional Report. Available: http://cdn.nmc.org/media/2015-nmc-technologyoutlook-brazilian-universities-EN.pdf. 6 April, 2017.

Pegrum. M. (2014), New language learning \& teaching environments -mobile learning, languages, literatures and cultures. Springer.

Pisa, S.H., \& Goulart, E.E. A apropriação do WhatsApp como recurso inovador no curso de formação de professores. Master Thesis. Municipal University of Sao Caetano do Sul, Master Program in Communication. Available: < http://repositorio.uscs.edu.br/handle/123456789/990>.

Redecker, C. Leis. M. Leendertse, M. Punie, Y. Gijsbers, Y. Kirschner, P. Stoyanov, S. Hoogveld, B. (2011). The Future of Learning: Preparing for Change. European Commission. JRC Scientific and technical reports. EUR 24960 EN. doi: $10.2791 / 64117$.

Schuler, C., Winters, N., \& West, M. (2012). The future of mobile learning: Implications for policy makers and planners. Paris: UNESCO.

Traxler. J. \& Kukulska-Hulme. A. (2016). Mobile learning -The next generation. Introduction to the next generation of mobile learning. Routledge.

The United Nations Educational, Scientific and Cultural Organization (UNESCO). (2013). Kraut. R. (edit.), UNESCO policy guidelines for mobile learning. Available: http://unesdoc.unesco.org/images/0021/002196/219641E.pdf . 13 April, 2017. 